\title{
A comprehensive multivariate model of biopsychosocial factors associated with opioid misuse and use disorder in a 2017- 2018 United States national survey
}

Francisco A. Montiel Ishino ${ }^{1,3^{*}}$, Philip R. McNab ${ }^{2} \mathbb{D}$, Tamika Gilreath ${ }^{3} \mathbb{D}$, Bonita Salmeron ${ }^{1}$ and Faustine Williams ${ }^{1}$ (D)

\begin{abstract}
Background: Few studies have comprehensively and contextually examined the relationship of variables associated with opioid use. Our purpose was to fill a critical gap in comprehensive risk models of opioid misuse and use disorder in the United States by identifying the most salient predictors.

Methods: A multivariate logistic regression was used on the 2017 and 2018 National Survey on Drug Use and Health, which included all 50 states and the District of Columbia of the United States. The sample included all noninstitutionalized civilian adults aged 18 and older ( $N=85,580$; weighted $N=248,008,986)$. The outcome of opioid misuse and/or use disorder was based on reported prescription pain reliever and/or heroin use dependence, abuse, or misuse. Biopsychosocial predictors of opioid misuse and use disorder in addition to sociodemographic characteristics and other substance dependence or abuse were examined in our comprehensive model. Biopsychosocial characteristics included socioecological and health indicators. Criminality was the socioecological indicator. Health indicators included self-reported health, private health insurance, psychological distress, and suicidality. Sociodemographic variables included age, sex/gender, race/ethnicity, sexual identity, education, residence, income, and employment status. Substance dependence or abuse included both licit and illicit substances (i.e., nicotine, alcohol, marijuana, cocaine, inhalants, methamphetamine, tranquilizers, stimulants, sedatives).

(Continued on next page)
\end{abstract}

\footnotetext{
* Correspondence: francisco.montielishino@nih.gov

${ }^{1}$ Division of Intramural Research, National Institute on Minority Health and Health Disparities, National Institutes of Health, 7201 Wisconsin Ave Ste. 533, Bethesda, MD 20814, USA

${ }^{3}$ Transdisciplinary Center for Health Equity Research, College of Education and Human Development, Texas A\&M University, 4243 TAMU, 311 Blocker, College Station, TX 77843, USA

Full list of author information is available at the end of the article
}

(c) The Author(s). 2020 Open Access This article is licensed under a Creative Commons Attribution 4.0 International License, which permits use, sharing, adaptation, distribution and reproduction in any medium or format, as long as you give appropriate credit to the original author(s) and the source, provide a link to the Creative Commons licence, and indicate if changes were made. The images or other third party material in this article are included in the article's Creative Commons licence, unless indicated otherwise in a credit line to the material. If material is not included in the article's Creative Commons licence and your intended use is not permitted by statutory regulation or exceeds the permitted use, you will need to obtain permission directly from the copyright holder. To view a copy of this licence, visit http://creativecommons.org/licenses/by/4.0/ The Creative Commons Public Domain Dedication waiver (http://creativecommons.org/publicdomain/zero/1.0/) applies to the data made available in this article, unless otherwise stated in a credit line to the data. 


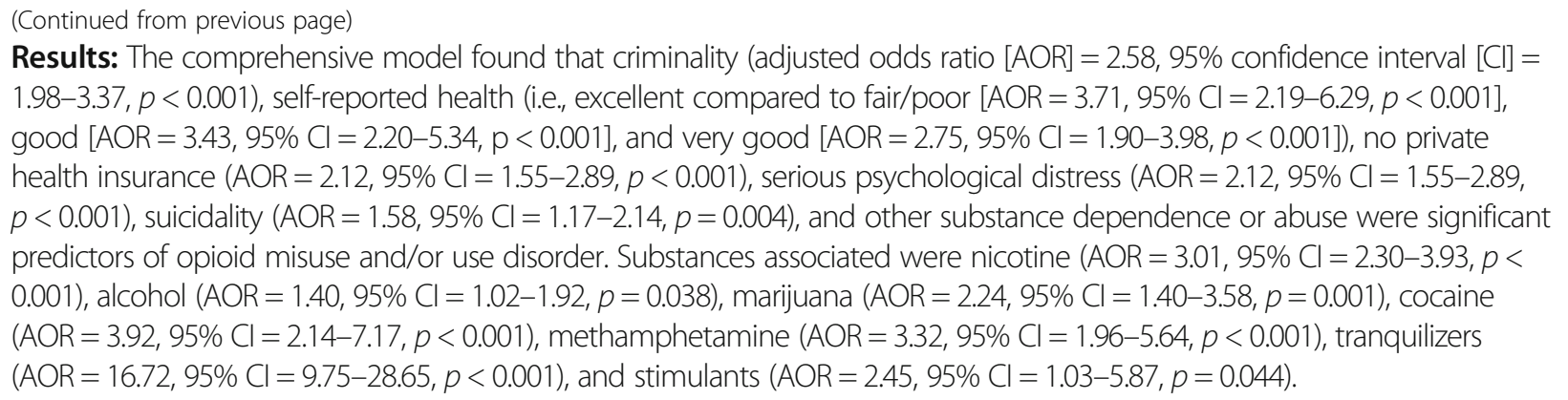

Conclusions: Biopsychosocial characteristics such as socioecological and health indicators, as well as other substance dependence or abuse were stronger predictors of opioid misuse and use disorder than sociodemographic characteristics.

Keywords: Opioids, Opioid misuse, Opioid use disorder, Biopsychosocial factors, Comprehensive risk

\section{Background}

Estimates indicate that up to $29 \%$ of persons misuse prescription pain relievers for chronic pain, [1] and between 8 to $12 \%$ develop a use disorder [2,3]. The United States (US) Department of Health and Human Services declared the opioid crisis a public health emergency in 2017, although the first wave of the epidemic emerged in the 1990s [3]. Opioid related deaths increased 345\% between 2001 to 2016 [4]. Subsequently, between July 2016 and September 2017 deaths due to illicit opioid overdose increased by $30 \%$, leading to an emergency declaration in 45 states [4].

Projections indicate that if current prevention and intervention strategies do not change by 2025 , the rate of misuse and overdose death will rise by $61 \%$ [5]. In response to the epidemic, multiple federal, state, and local agencies have implemented various strategies to address the opioid crisis. Increasing the availability of naloxone-a medication that reverses the effects of an overdose-is projected to reduce opioid-related deaths by approximately $4 \%$ according to the most recent projections [6]. Other interventions like reduced prescribing for pain patients and excess opioid management can increase life years and quality-adjusted life years, but overdose deaths would increase among those with opioid dependence due to a move from prescription opioids to heroin [6]. Overall, supply-side prevention strategies are estimated to have minimal impact, preventing only 3.0 to $5.3 \%$ of overdose deaths [6].

As current interventions are inadequately addressing the multidimensional and far-reaching nature of the opioid epidemic [5, 6], some scholars have suggested developing more tailored approaches to reach specific, underrepresented populations [7]. Non-Hispanic whites, for instance, have become the primary focus for multiple prevention programs and strategies as they have been found to misuse opioid at greater rates [8-10]. However, multiple racial/ethnic groups have been found to be at differential risk, as well as differentially affected by opioid misuse [8-10].

Opioid misuse and/or use disorder are also linked to other risk factors besides race and ethnicity. Scholl et al. [9] found that younger age was a significant predictor of misuse. The current opioid misuse and/or use disorder literature has also found that race/ethnicity and age become less predictive of misuse when they are considered in the context of other biopsychosocial factors such as sex and gender. For instance, Nicholson and Vincent [11] observed that Black women with lower socioeconomic status had an increased the probability of misuse, while older age, higher educational attainment, and rural residence were associated with a lower probability [11, 12].

Other biopsychosocial factors like criminality and sexual identity, although understudied, have been associated with misuse and/or use disorder [13, 14]. For instance, Pierce et al. [13] found that individuals testing positive for opioid use had higher rates of criminality-though the relationship was strongest for less serious crimes. Sexual minorities, such as those identifying as gay/lesbian or bisexual, have also been reported to be at risk of opioid misuse [14-16]. For instance, Duncan et al. [14] found that, compared to heterosexuals, those identifying as bisexual or gay/lesbian were at 78 and $115 \%$ increased odds of misuse, respectively.

General health and access to healthcare have a role in opioid misuse and/or use disorder, but most research has focused on hospitalized subpopulations and physical pain $[1,17,18]$, which will not be covered here. The general health and access to healthcare relationship, however, is less clear among noninstitutionalized populations. One particular aspect of healthcare access in the form of health insurance is believed to have a role in opioid misuse. Some studies argue that health insurance companies may facilitate opioid misuse [19], whereas others have observed that an increase in health 
insurance coverage was linked to a reduction in opioidrelated deaths [20]. Mental health is another facet of health for which there is an unclear relationship with opioid misuse and/or use disorder, as specific disorders may influence the association differently. Nevertheless, opioid misuse and/or use disorder has been found to be associated with severe mental illness like depression and anxiety [21, 22], as well as suicidality [22-24].

Concurrent substance use such as nicotine and tobacco dependence [25, 26], alcohol [27], sedatives [28], methamphetamines [29], tranquilizers [30-32], other analgesics [33], and marijuana [34] have been positively associated with opioid misuse and use disorder [34, 35]. Marijuana's association may be context dependent, as it has a mixed relationship with opioid use, misuse, and use disorder [36]. Polysubstance abuse must be critically assessed in context of opioid use as multiple associations may exist due to the varied effects of synergizing the opioid high. A better understanding of how polysubstance abuse occurs in context of multiple social and environmental factors is critical [28, 29, 37].

We hypothesized that sociodemographic factors, while crucial to the comprehensive risk model, would not be critical predictors, when they were included with socioecological and health factors, or with other substance dependence or abuse. The purpose of this study was to fill in a critical gap in the literature to improve population-level prevention strategies by identifying the most salient predictors of opioid misuse and/or use disorder.

\section{Methods}

While epidemiologic studies have examined the relationship of various risk factors on opioid misuse and use disorder among non-institutionalized populations, comprehensive models are relatively absent. To address the opioid epidemic, we need to identify the risk factors associated with the etiology of misuse to intervene at multiple levels, tailor interventions for specific populations, and prevent the distal events of use disorder like overdose. In response to this need, we comprehensively examined the relationship of opioid misuse and/or use disorder and biopsychosocial characteristics using four domains: (1) sociodemographic factors; (2) socioecological factors (e.g., criminality); (3) health factors (e.g., self-reported general health; mental health, suicidality; access to health services); and (4) other substance dependence or abuse. We took this approach to determine the most salient risk factors for opioid misuse and/or use disorder in a representative, noninstitutionalized US adult sample.

We used multivariate logistic regression on the combined 2017 [38] and 2018 [39] National Survey on Drug Use and Health (NSDUH) to examine the relationship of biopsychosocial characteristics and opioid misuse and/or use disorder. Opioid misuse was characterized as heroin use and/or prescription pain reliever misuse in the past year based on NSDUH definitions [40]. Individuals taking prescribed pain relievers may develop a tolerance to pain relief that can lead to taking the prescription at higher doses and/or more frequently than prescribed, which would constitute misuse [40]. Furthermore, heroin was included with misuse as any opioid creates the same adverse effects as prescription pain relievers, which in turn may develop into opioid use disorder [40]. Use disorder was characterized by heroin use disorder, prescription pain reliever use disorder, or heroin and prescription pain reliever use disorder, as they may not be mutually exclusive in the NSDUH [40]. Biopsychosocial characteristics, as well as sociodemographic and other substance dependence or abuse were tested independently in unadjusted models. Adjusted models were then built using a block entry method to test biopsychosocial characteristics on opioid misuse and/or misuse disorder in the following order: (Model 1) sociodemographic indicators; (Model 2) socioecological indicator; (Model 3) health indicators; and (Model 4) other substance dependence or abuse. All variables were retained as controls and covariates in subsequent models. We accounted for the complex survey design of the NSDUH by the strata and clusters provided, as well as adjusting the analytical weights to account for two years. All analyses were conducted with Stata 16 (StataCorp LLC, College Station, TX). The study received exemption from the Institutional Review Board, as no human participants were involved in this research. The analysis was not preregistered, and the results should be considered exploratory.

\section{Sociodemographic variables and factors}

Five age categories were used: (1) 18 to 25; (2) 26 to 34; (3) 35 to 49; (4) 50 to 64; and (5) 65 and older. The binary category of male and female was used for sex/gender. Race/ethnicity was divided into seven categories: (1) non-Hispanic white; (2) non-Hispanic Black/African American; (3) non-Hispanic Native American/Alaska Native; (4) non-Hispanic Native Hawaiian/other Pacific Islander; (5) non-Hispanic Asian; (6) non-Hispanic more than one race; and (7) Hispanic. Sexual identity had three categories: (1) heterosexual; (2) gay/lesbian; and (3) bisexual. Place of residence was based on 2009 CoreBased Statistical Areas (CBSAs) defined by the Office of Management and Budget [41]: (1) CBSA with 1 million or more persons; (2) CBSA with fewer than 1 million persons; and (3) segment not in a CBSA. Total family income was divided into four categories: (1) less than $\$ 20$, 000 ; (2) $\$ 20,000$ to $\$ 49,999$; (3) $\$ 50,000$ to $\$ 74,999$; and (4) $\$ 75,000$ or more. Employment status was divided 
into five categories: (1) full-/part-time job; (2) unemployed; (3) retired; (4) disabled; and (5) other which included keeping house full time and in school/training. Educational attainment was divided into four categories: (1) less than high school; (2) high school graduate; (3) some college/associate's degree; and (4) college graduate.

\section{Socioecological factors}

The criminality variable was based on if the participant had been arrested and booked for breaking the law, excluding minor traffic violations. Booked was defined as being taken into custody and processed by the legal system, even if the participant was later released.

\section{Health factors}

Health factors included overall perceived health, having access to private health insurance, and mental health indicators. Overall self-reported health was categorized as (1) excellent, (2) very good, (3) good, and (4) fair/poor. The private health insurance category was based on if respondent had obtained it through (1) employment by paying premiums to an insurance company; (2) the Health Insurance Marketplace; or (3) a health maintenance organization (HMO), fee-for-service plans, or single-service plans. The mental health indicators were severe psychological distress and suicidality. A severe psychological distress indicator within the past year was based on responses from past-month Kessler-6 (K6) items and the worst month in the past-year K6 items. K6 items are from a screening instrument for nonspecific psychological distress developed by Furukawa, Kessler, Slade, and Andrews, [42] and Kessler et al. [43] Suicidality was assessed if at any time in the past year a participant had seriously thought about trying to commit suicide.

\section{Substance misuse, dependence, and/or abuse factors}

The outcome of opioid misuse and/or use disorder was defined as misuse and/or dependence or abuse of prescription pain relievers and/or heroin use in the past year. Opioid use disorder was classified using the Diagnostic and Statistical Manual of Mental Disorders, 4th edition (DSM-IV) criteria for dependence or abuse criteria based on heroin use disorder, prescription pain reliever use disorder, or heroin and prescription pain reliever use disorder in the past year based on NSDUH methodology and terminology [See https:// www.samhsa.gov/data/sites/default/files/cbhsq-reports/ NSDUHMethodsSummDefs2018/NSDUHMethodsSummDefs2018.pdf]. While opioid substance use disorder was classified under the DSM-V, the NSDUH used the DSM-IV criteria of dependence or abuse, as such we opted to use the DSM-V terminology $[15,18]$. Nicotine dependence in the past month was assessed using Nicotine Dependence Syndrome Scale scores and the Fagerstrom Test of Nicotine
Dependence scale in the past month. Alcohol dependence and abuse in the last year was also ascertained. Dependence and abuse in the past year were also determined for marijuana, cocaine, hallucinogens, inhalants, methamphetamine, tranquilizers, stimulants (i.e., independent of methamphetamine), and sedatives [44].

\section{Statistical analysis}

We performed descriptive analyses to detail the characteristics of NSDUH sample participants. We checked the data for normality of the residuals, homoscedasticity, multicollinearity, outliers and influence. After the data were found to be adequate for the logistic regression model, four weighted multivariate models were built using Stata survey procedure. All models were weighted and accounted for clustering and stratification of the complex survey design. All findings are reported in odds ratios (ORs) or adjusted odds ratios (AORs) using a 95\% confidence interval $(\mathrm{CI})$ and $p$-value for significance criteria.

\section{Results \\ Sample characteristics}

The sample consisted of 85,580 individuals (weighted $N=$ $248,008,986$ ) over the age of 18 . Male and female participants were represented about equally- $48 \%$ male (weighted $N=119,711,438$ ) and $52 \%$ female (weighted $N=119,711,438)$. The majority of the weighted sample was non-Hispanic white $(63.6 \%)$, resided in a high population density CBSA (54.1\%), identified as heterosexual (94.8\%), had a family income of $\$ 75,000$ or more $(38.9 \%)$, were college graduates $(32.1 \%)$, were employed (62.7\%), had no history of arrest and booking $(83.4 \%)$, were in very good health (36.1\%), had private health insurance (66.6\%), had no serious psychological distress in past year (88.6\%), and displayed no suicidality (95.7\%). See Table 1 for a detailed breakdown of the sample's characteristics.

Of the sample, 865 individuals (weighted $N=1,976$, 471) reported opioid misuse. Other substances that the sample had dependence on or abused were nicotine, alcohol, marijuana, cocaine, inhalants, methamphetamine, tranquilizers, stimulants, hallucinogens, and sedatives. See Table 2 for a complete report of the sample's substance dependence and abuse profile.

\section{Logistic regression \\ Independent unadjusted models}

All sociodemographic and biopsychosocial characteristics, as well as other substance dependence or abuse were tested independently in unadjusted models to examine the relationship of each characteristic on opioid misuse. All characteristics tested with exception of residence at some level were found to be a significant factor predictive of opioid misuse. See Table 3 for all associations. 
Table 1 Descriptive characteristics of biopsychical indicators using the 2017-2018 NSDUH $(N=85,580 ;$ Weighted $N=248,008,986)$

\begin{tabular}{|c|c|c|c|}
\hline & $N$ & Weighted $N$ & $\%$ \\
\hline \multicolumn{4}{|l|}{ Age Groups } \\
\hline 18-25 years old & 27,477 & $34,171,330$ & $13.8 \%$ \\
\hline $26-34$ years old & 17,580 & $39,791,188$ & $16.0 \%$ \\
\hline $35-49$ years old & 22,902 & $61,084,084$ & $24.6 \%$ \\
\hline 50-64 years old & 9935 & $62,285,999$ & $25.1 \%$ \\
\hline 65 or older & 7686 & $50,676,385$ & $20.4 \%$ \\
\hline \multicolumn{4}{|l|}{ Sex/Gender } \\
\hline Male & 40,156 & $119,711,438$ & $48.3 \%$ \\
\hline Female & 45,424 & $128,297,548$ & $51.7 \%$ \\
\hline \multicolumn{4}{|l|}{ Race/Ethnicity } \\
\hline Non-Hispanic White & 51,704 & $157,708,305$ & $63.6 \%$ \\
\hline Non-Hispanic Black/African American & 10,630 & $29,520,476$ & $11.9 \%$ \\
\hline Native American/Alaska Native & 1220 & $1,387,749$ & $0.6 \%$ \\
\hline Native Hawaiian/other Pacific Islander & 417 & 939,268 & $0.4 \%$ \\
\hline Non-Hispanic Asian & 4190 & $14,061,853$ & $5.7 \%$ \\
\hline Non-Hispanic more than one race & 2786 & $4,250,536$ & $1.7 \%$ \\
\hline Hispanic & 14,633 & $40,140,798$ & $16.2 \%$ \\
\hline \multicolumn{4}{|l|}{ Area of Residence by Population Density } \\
\hline Segment in a CBSA > 1 million & 36,272 & $134,292,992$ & $54.1 \%$ \\
\hline Segment in a CBSA $<1$ million & 42,433 & $99,166,152$ & $40.0 \%$ \\
\hline Segment not in a CBSA & 6875 & $14,549,842$ & $5.9 \%$ \\
\hline \multicolumn{4}{|l|}{ Sexual Identity } \\
\hline Heterosexual, i.e., straight & 77,811 & $230,292,107$ & $94.8 \%$ \\
\hline Lesbian or gay & 1884 & $4,774,123$ & $2.0 \%$ \\
\hline Bisexual & 4204 & $7,875,005$ & $3.2 \%$ \\
\hline \multicolumn{4}{|l|}{ Family Income } \\
\hline Less than $\$ 20,000$ & 16,488 & $39,520,535$ & $15.9 \%$ \\
\hline$\$ 20,000-\$ 49,999$ & 26,460 & $72,948,368$ & $29.4 \%$ \\
\hline$\$ 50,000-\$ 74,999$ & 13,376 & $38,994,110$ & $15.7 \%$ \\
\hline$\$ 75,000$ or more & 29,256 & $96,545,973$ & $38.9 \%$ \\
\hline \multicolumn{4}{|l|}{ Level of Education } \\
\hline Less than high school & 10,832 & $30,482,047$ & $12.3 \%$ \\
\hline High school graduate & 22,532 & $61,032,429$ & $24.6 \%$ \\
\hline Some college/associate's degree & 28,608 & $76,994,245$ & $31.0 \%$ \\
\hline College graduate & 23,608 & $79,500,265$ & $32.1 \%$ \\
\hline \multicolumn{4}{|l|}{ Employment Status (past week) } \\
\hline Employed full/part-time & 57,686 & $153,914,559$ & $62.7 \%$ \\
\hline Unemployed & 4840 & $10,241,227$ & $4.2 \%$ \\
\hline Retired & 6329 & $41,374,848$ & $16.9 \%$ \\
\hline Disabled & 3035 & $11,545,013$ & $4.7 \%$ \\
\hline Other & 12,717 & $28,404,275$ & $11.6 \%$ \\
\hline \multicolumn{4}{|l|}{ Ever Arrested and Booked } \\
\hline No & 70,625 & $205,996,442$ & $83.4 \%$ \\
\hline Yes & 14,628 & $41,013,634$ & $16.6 \%$ \\
\hline
\end{tabular}


Table 1 Descriptive characteristics of biopsychical indicators using the 2017-2018 NSDUH $(N=85,580$; Weighted $N=248,008,986)$ (Continued)

\begin{tabular}{|c|c|c|c|}
\hline & $N$ & Weighted $N$ & $\%$ \\
\hline \multicolumn{4}{|c|}{ Overall Health Status } \\
\hline Fair/poor & 9675 & $34,313,374$ & $13.8 \%$ \\
\hline Good & 23,960 & $72,114,751$ & $29.1 \%$ \\
\hline Very good & 32,368 & $89,447,218$ & $36.1 \%$ \\
\hline Excellent & 19,555 & $52,070,096$ & $21.0 \%$ \\
\hline \multicolumn{4}{|c|}{ Covered by Private Health Insurance } \\
\hline No & 30,721 & $82,568,583$ & $33.4 \%$ \\
\hline Yes & 54,422 & $164,350,599$ & $66.6 \%$ \\
\hline \multicolumn{4}{|c|}{ Serious Psychological Distress Indicator (past year) } \\
\hline No & 72,141 & $219,851,056$ & $88.6 \%$ \\
\hline Yes & 13,439 & $28,157,930$ & $11.4 \%$ \\
\hline \multicolumn{4}{|c|}{ Suicidality (past year) } \\
\hline No & 79,598 & $235,697,531$ & $95.7 \%$ \\
\hline Yes & 5327 & $10,703,135$ & $4.3 \%$ \\
\hline
\end{tabular}

\section{Adjusted multivariate logistic regression models}

Model 1 found that sociodemographic factors such as age, sex/gender, race/ethnicity, sexual identity, educational attainment, family income, and employment status were positively associated with opioid misuse. In Model 2 , we added the socioecological factor of past criminality, which was positively associated with opioid misuse, while controlling for sociodemographic factors. In Model 3 , health factors such as overall reported health, serious psychological distress in past year, suicidality in the past year, and not having private health insurance were added (while controlling for sociodemographic and socioecological factors) and were positively associated with opioid misuse. In Model 4, other substance dependence and abuse were added to the model, which was controlled for sociodemographic, socioecological, and health factors. Model 4 was selected for interpretation.

\section{Comprehensive model of opioid misuse}

Compared to no prior history, having past criminality was associated with significantly increased odds of opioid misuse (adjusted odds ratio $[\mathrm{AOR}]=2.58$, 95\% confidence interval $[\mathrm{CI}]: 1.98-3.37, p<0.001)$. Overall selfreported health status was associated with opioid misuse when individuals reported fair/poor $(\mathrm{AOR}=3.71,95 \%$ $\mathrm{CI}: 2.19-6.29, p<0.001)$, good $(\mathrm{AOR}=3.43,95 \% \mathrm{CI}$ : $2.20-5.34, p<0.001)$, and very good health $(\mathrm{AOR}=2.75$, 95\% CI: $1.90-3.98, p<0.001)$ compared to those that reported excellent health. Among individuals with no private health insurance, there was 2.12 increased adjusted odds (95\% CI: $1.55-2.89, p<0.001$ ) of opioid misuse compared to participants with health insurance. Similarly, participants who experienced past serious psychological distress or suicidality had 3.05 adjusted odds (95\% CI: $2.20-4.23, p<0.001)$ and 1.58 odds $(95 \%$ CI: $1.17-2.14, p=0.004)$ of opioid misuse, respectively, when compared to those with no history. Participants exhibiting substance dependence or abuse, with the notable exception of inhalants and sedatives, were positively associated with increased adjusted odds of opioid misuse compared to those with no substance dependence or abuse (nicotine: AOR $=3.01,95 \%$ CI: 2.30-3.93, $p<$ 0.001; alcohol: $\mathrm{AOR}=1.40,95 \% \mathrm{CI}: 1.02-1.92, p=0.038$; marijuana: $\mathrm{AOR}=2.24,95 \% \mathrm{CI}: 1.40-3.58, p=0.001$; cocaine: $\mathrm{AOR}=3.92,95 \% \mathrm{CI}: 2.14-7.17 p<0.001$; methamphetamine: $\mathrm{AOR}=3.32,95 \% \mathrm{CI}: 1.96-5.64 p<0.001$; tranquilizers: $\mathrm{AOR}=16.7,95 \% \mathrm{CI}:$ 9.75-28.7, $p<0.001$; stimulants: $\mathrm{AOR}=2.45,95 \% \mathrm{CI}: 1.03-5.87, p=0.044)$. See Table 4 for more detail.

\section{Discussion}

Opioid misuse and use disorder prevention strategies and programs must focus on multiple associated risk factors in the context of the person and their environment to ameliorate the ongoing epidemic. As epidemics do not occur in a vacuum, we accounted for the biopsychosocial characteristics associated with opioid misuse and/or use disorder. Sociodemographic, socioecological, and health factors, as well as other substance dependence or abuse were found to be independently significant for opioid misuse and/or use disorder. However, we found in our comprehensive model that socioecological indicators like criminality, health status factors including serious psychological distress and suicidality, and private health insurance were significant risk characteristics, as well as nicotine, alcohol, marijuana, cocaine, 
Table 2 Descriptive characteristics of substance dependence or abuse from the 2017-2018 NSDUH ( $N=85,580$; Weighted $N=$ $248,008,986)$

\begin{tabular}{|c|c|c|c|}
\hline & $N$ & Weighted $N$ & $\%$ \\
\hline \multicolumn{4}{|c|}{ Nicotine dependence (past month) } \\
\hline No & 75,397 & $221,362,313$ & $89.26 \%$ \\
\hline Yes & 10,183 & $26,646,673$ & $10.74 \%$ \\
\hline \multicolumn{4}{|c|}{ Alcohol dependence or abuse (past year) } \\
\hline No/Unknown & 79,239 & $133,842,026$ & $94.29 \%$ \\
\hline Yes & 6341 & $14,166,959$ & $5.71 \%$ \\
\hline \multicolumn{4}{|c|}{ Marijuana dependence or abuse (past year) } \\
\hline No/Unknown & 83,439 & $244,355,720$ & $98.53 \%$ \\
\hline Yes & 2141 & $36,532,266$ & $1.47 \%$ \\
\hline \multicolumn{4}{|c|}{ Cocaine dependence or abuse (past year) } \\
\hline No/Unknown & 85,147 & $247,063,145$ & $99.62 \%$ \\
\hline Yes & 433 & 945,841 & $0.38 \%$ \\
\hline \multicolumn{4}{|c|}{ Inhalant dependence or abuse (past year) } \\
\hline No & 85,535 & $247,914,187$ & $99.96 \%$ \\
\hline Yes & 45 & 94,798 & $0.04 \%$ \\
\hline \multicolumn{4}{|c|}{ Methamphetamine dependence or abuse (past year) } \\
\hline No & 85,146 & $246,985,929$ & $99.59 \%$ \\
\hline Yes & 434 & $1,023,057$ & $0.41 \%$ \\
\hline \multicolumn{4}{|c|}{ Tranquilizer dependence or abuse (past year) } \\
\hline No & 85,260 & $247,362,108$ & $99.74 \%$ \\
\hline Yes & 320 & 646,877 & $0.26 \%$ \\
\hline \multicolumn{4}{|c|}{ Stimulant dependence or abuse (past year) } \\
\hline No & 85,309 & $247,499,633$ & $99.79 \%$ \\
\hline Yes & 271 & 509,353 & $0.21 \%$ \\
\hline \multicolumn{4}{|c|}{ Sedative dependence or abuse (past year) } \\
\hline No & 85,519 & $247,855,708$ & $99.94 \%$ \\
\hline Yes & 61 & 153,278 & $0.06 \%$ \\
\hline \multicolumn{4}{|c|}{ Opioid dependence or abuse (past year) } \\
\hline No & 84,715 & $246,032,515$ & $99.20 \%$ \\
\hline Yes & 865 & $1,976,471$ & $0.80 \%$ \\
\hline
\end{tabular}

methamphetamine, tranquilizer, and stimulant dependence or abuse.

In our comprehensive biopsychosocial model we observed that sociodemographic factors functioned as controls rather than predictors for opioid misuse and/or use disorder. While other studies have focused on sociodemographic factors for describing risk in opioid misuse and overdose death $[8,9,37,45,46]$, our model further revealed the significance of accounting for socioecological and health related risk factors in context of opioid misuse and/or use disorder. Our findings were similar to a study by Mojtabai, Amin-Esmaeili, Nejat, and Olfson [47] that found prescribed-opioid misuse was associated with criminality, mental health distress, and other substance abuse or dependence. Similarly, a study by Grigsby and Howard [34] discovered that prescription opioid and polysubstance users had the greatest probability of past-year criminality and mental health distress.

The relationship of opioid misuse and/or use disorder, mental health distress, and socioecological factors like criminality are complex, and may be co-occurring. To understand this risk process we can look to a study by Prince [22], which found that individuals with opioid misuse disorder who had a severe mental illness were at an increased risk of criminality and suicidality. The risk increased for those using only heroin, both heroin and prescription opioids, and all other substances, in that order [22]. Moreover, we found that common mental health disorders such as major depression, dysthymia, generalized anxiety disorder, or panic disorder in the general population predicted a $96 \%$ increase in prescribed opioid use [48]. While the relationship between criminality, mental health, and substance use is notable for developing tailored interventions, an overemphasis on this link may also perpetuate harmful stigma and mask important underlying factors. For example, adverse childhood experiences may contribute to all three: criminality, mental health disorders, and opioid misuse and use disorder [49-51].

Of note from our findings was that race/ethnicity in the presence of other socioecological and health factors related to polysubstance use may not be strongly associated with polysubstance dependence/abuse and opioid misuse and/or use disorder [52]. For instance, we found non-Hispanic Whites, American Indian/Alaska Natives, and non-Hispanic multiracial individuals were a significant group until polysubstance dependence/abuse was accounted for in the comprehensive model, but it may be explainable by other contextual factors [53, 54]. Whites, for example, are often prescribed more opioids compared to their Non-Hispanic Black counterparts, regardless of genuine clinical need [53]. Furthermore, other possibilities to consider between and within racial/ ethnic groups are access to illicit drugs for purchase and use of drugs by friends and family members, as well as adverse childhood experiences or trauma [51, 55-57].

Other substance dependence or abuse has been associated with opioid misuse based on various risk factors $[11,25,30,45,58]$. In our study, we found that nicotine $[25,26]$, alcohol [25, 27], cocaine [58], methamphetamine [29], tranquilizers [31, 32, 59], other illicit stimulants [15], and marijuana [25] have a positive relationship with opioid misuse and use disorder. The stimulant effect from nicotine, cocaine, methamphetamine, and other illicit stimulants may mitigate the depressive effects of opioids and may increase the "high" effect [29]. Substances such as tranquilizers have been 
Table 3 Odds ratios, 95\% confidence intervals, and $p$-values of independent biopsychosocial indicators and other substance dependence or abuse on opioid misuse: 2017-2018 National Survey on Drug Use and Health

\begin{tabular}{|c|c|c|c|c|}
\hline & \multirow[t]{2}{*}{ OR } & \multicolumn{2}{|l|}{$95 \% \mathrm{Cl}$} & \multirow[t]{2}{*}{$p$-value } \\
\hline & & Lower & Upper & \\
\hline \multicolumn{5}{|l|}{ Age } \\
\hline 18-25 years old & 6.55 & 3.10 & 13.83 & 0.000 \\
\hline 26-34 years old & 7.97 & 3.77 & 16.84 & 0.000 \\
\hline $35-49$ years old & 4.95 & 2.33 & 10.52 & 0.000 \\
\hline 50-64 years old & 4.86 & 2.35 & 10.04 & 0.000 \\
\hline 65 years and older & ref. & - & - & - \\
\hline \multicolumn{5}{|l|}{ Sex/Gender } \\
\hline Male & 1.43 & 1.14 & 1.80 & 0.003 \\
\hline Female & ref. & - & - & - \\
\hline \multicolumn{5}{|l|}{ Race/Ethnicity } \\
\hline Non-Hispanic White & 5.15 & 2.31 & 11.46 & 0.000 \\
\hline Non-Hispanic Black/African American & 3.95 & 1.60 & 9.77 & 0.004 \\
\hline Native American/Alaska Native & 8.64 & 3.28 & 22.75 & 0.000 \\
\hline Native Hawaiian/Pacific Islander & 3.39 & 0.65 & 17.61 & 0.142 \\
\hline Non-Hispanic more than one race & 7.48 & 2.84 & 19.65 & 0.000 \\
\hline Hispanic & 3.18 & 1.42 & 7.12 & 0.006 \\
\hline Non-Hispanic Asian & ref. & - & - & - \\
\hline \multicolumn{5}{|l|}{ Sexual Identity } \\
\hline Lesbian or gay & 1.21 & 0.70 & 2.08 & 0.484 \\
\hline Bisexual & 2.70 & 1.89 & 3.84 & 0.000 \\
\hline Heterosexual, i.e., straight & ref. & - & - & - \\
\hline \multicolumn{5}{|l|}{ Educational attainment } \\
\hline Less than high school & 4.01 & 2.54 & 6.34 & 0.000 \\
\hline High school grad & 3.55 & 2.30 & 5.49 & 0.000 \\
\hline Some college/associate's degree & 2.75 & 1.79 & 4.24 & 0.000 \\
\hline College graduate & ref. & - & - & - \\
\hline \multicolumn{5}{|l|}{ Family Income } \\
\hline Less than $\$ 20,000$ & 3.55 & 2.57 & 4.91 & 0.000 \\
\hline$\$ 20,000-\$ 49,999$ & 1.95 & 1.44 & 2.64 & 0.000 \\
\hline$\$ 50,000-\$ 74,999$ & 1.56 & 1.08 & 2.26 & 0.020 \\
\hline$\$ 75,000$ or more & ref. & - & - & - \\
\hline \multicolumn{5}{|l|}{ Population Density } \\
\hline Segment in a CBSA $>1$ million & 0.80 & 0.55 & 1.17 & 0.248 \\
\hline Segment in a CBSA $<1$ million & 0.99 & 0.69 & 1.40 & 0.936 \\
\hline Segment not in a CBSA & ref. & - & - & - \\
\hline \multicolumn{5}{|l|}{ Employment (past week) } \\
\hline Employed full/part-time & ref. & - & - & - \\
\hline Unemployed & 4.23 & 3.11 & 5.76 & 0.000 \\
\hline Retired & 0.29 & 0.14 & 0.59 & 0.001 \\
\hline Disabled & 4.10 & 2.88 & 5.84 & 0.000 \\
\hline Other & 1.85 & 1.44 & 2.37 & 0.000 \\
\hline
\end{tabular}


Table 3 Odds ratios, 95\% confidence intervals, and $p$-values of independent biopsychosocial indicators and other substance dependence or abuse on opioid misuse: 2017-2018 National Survey on Drug Use and Health (Continued)

\begin{tabular}{|c|c|c|c|c|}
\hline & OR & $95 \% \mathrm{Cl}$ & & $p$-value \\
\hline & & Lower & Upper & \\
\hline No & ref. & - & - & \\
\hline Yes & 7.73 & 6.18 & 9.68 & 0.000 \\
\hline Overall Health St & & & & \\
\hline Fair/Poor & 10.70 & 7.25 & 15.78 & 0.000 \\
\hline Good & 6.15 & 4.17 & 9.05 & 0.000 \\
\hline Very Good & 3.52 & 2.49 & 4.96 & 0.000 \\
\hline Excellent & ref. & - & - & \\
\hline Serious Psycholo & & & & \\
\hline No & ref. & - & - & \\
\hline Yes & 9.15 & 7.55 & 11.08 & 0.000 \\
\hline Suicidality in Past & & & & \\
\hline No & ref. & - & - & \\
\hline Yes & 8.14 & 6.61 & 10.04 & 0.000 \\
\hline Private Health Ins & & & & \\
\hline No & 4.14 & 3.34 & 5.14 & 0.000 \\
\hline Yes & ref. & - & - & \\
\hline Nicotine Depend & & & & \\
\hline No & ref. & - & - & - \\
\hline Yes & 10.46 & 8.44 & 12.96 & 0.000 \\
\hline Alcohol Depende & & & & \\
\hline No/Unknown & ref. & - & - & - \\
\hline Yes & 5.80 & 4.72 & 7.13 & 0.000 \\
\hline Marijuana Depen & & & & \\
\hline No/Unknown & ref. & - & - & - \\
\hline Yes & 12.82 & 9.33 & 17.62 & 0.000 \\
\hline Cocaine Depend & & & & \\
\hline No/Unknown & ref. & - & - & - \\
\hline Yes & 45.16 & 31.87 & 64.00 & 0.000 \\
\hline Inhalant Depend & & & & \\
\hline No & ref. & - & - & - \\
\hline Yes & 51.00 & 18.24 & 142.58 & 0.000 \\
\hline Methamphetami & & & & \\
\hline No & ref. & - & - & - \\
\hline Yes & 51.88 & 36.77 & 73.21 & 0.000 \\
\hline Tranquilizer Depe & & & & \\
\hline No & ref. & - & - & - \\
\hline Yes & 145.51 & 112.02 & 189.02 & 0.000 \\
\hline Stimulant Depen & & & & \\
\hline No & ref. & - & - & - \\
\hline Yes & 68.84 & 40.61 & 116.67 & 0.000 \\
\hline Sedative Depend & & & & \\
\hline No & ref. & - & - & - \\
\hline
\end{tabular}


Table 3 Odds ratios, 95\% confidence intervals, and $p$-values of independent biopsychosocial indicators and other substance dependence or abuse on opioid misuse: 2017-2018 National Survey on Drug Use and Health (Continued)

\begin{tabular}{|c|c|c|c|c|}
\hline & \multirow[t]{2}{*}{ OR } & \multicolumn{2}{|l|}{$95 \% \mathrm{Cl}$} & \multirow[t]{2}{*}{$p$-value } \\
\hline & & Lower & Upper & \\
\hline Yes & 67.08 & 30.53 & 147.40 & 0.000 \\
\hline
\end{tabular}

reported to be used to heighten, maintain, and extend the effect of the "high" [31-33], which may explain the elevated odds ratio of 16.7 when compared to all other substance dependence or abuse. Further research would be necessary to capture this context. Tranquilizer dependence and abuse is also of particular note, as most opioid overdose reported in the US involved some type of tranquilizer-for example, benzodiazepines [60, 61].

Our study also revealed an increased association of opioid misuse and/or use disorder with marijuana compared to non-marijuana users. This relationship, however, has been found to have mixed associations in previous studies. In the cases of marijuana dependence or abuse there is a positive relationship with opioid misuse [34]. A more recent review found that medical marijuana use may decrease the probability of opioid use [36]. Campbell et al. [36] further revealed that medical cannabis laws may slow the increase of opioid overdose deaths in states with medical cannabis laws compared to states with none. Alcohol has been another substance with mixed associations for opioid misuse and use disorder. For instance, Fernandez et al. [27] reported that alcohol dependence or abuse was not associated with opioid misuse. We found, however, in our comprehensive adjusted model that alcohol dependence or abuse was associated with a higher probability for opioid misuse, in line with the findings of Witkiewitz et al. [62]. Overall, prevention strategies and prevention programs must focus on both the combined use of legal and illicit substances.

Our study used a comprehensive approach to understand how multiple biopsychosocial characteristics relate, in context, to opioid misuse and/or use disorder. Since the current opioid crisis is not unlike prior substance use disorder crises of the past, our goal was to provide data that can be used to inform primary, secondary, and tertiary prevention efforts along the continuum from opioid misuse to use disorder-with attention to particular groups and contextual factors. By identifying risk factors within our model, we were able to contextually examine biopsychosocial characteristics to inform future research and prevention strategies to intervene upon opioid use disorder and related distal outcomes for noninstitutionalized US adults. Tailored interventions could be effective for individuals reentering society from incarceration, experiencing unemployment, suffering from psychological distress, and/or using public health insurance [63]. Examples include reentry programs, jobs placement programs, and integrated mental health and substance abuse treatment [64-67]. Nonetheless, opioid use and misuse disorder may occur alongside use of other substances, and both the determinants and effects of concurrent use must be addressed by interventions [5]. Our hope is that our results do not perpetuate stigma but rather encourage the development of effective interventions for specific populations.

Lastly, our study using a biopsychosocial model elucidated that the opioid epidemic is not an epidemic as much a syndemic. The opioid syndemic involves multiple interacting social, health, and psychological factors with comorbid substance co-use that synergizes the negative effects of opioid misuse and/or use disorder $[68,69]$. Future interventions will need to acknowledge the opioid syndemic as multiple dynamic and complex factors and health outcomes that come as a result not only from misuse and/or use disorder, but policies and environmental contexts. As such, future studies will have to use complex models to move beyond onedimensional outcomes to understand the contextual issues of opioid misuse and/or use disorder and improve not only overdose outcomes but person-level quality of life.

\section{Limitations}

To our knowledge, this is the first US population-level study to comprehensively address risk profiles of opioid misuse using the latest national survey data available. Like most surveys of this kind, there are limitations to the NSDUH. The most prominent limitation is the use of self-reported data. These data are subject to the individual participant's bias, truthfulness, recollection, and knowledge. Second, although the data are nationally representative, the survey is cross-sectional, and it excludes some subsets of the population. The NSDUH only targets noninstitutionalized US citizens, so active-duty military members and institutionalized groups (e.g., prisoners, hospital patients, treatment center patients, and nursing home members) are excluded. Thus, if substance use differs between US noninstitutionalized and institutionalized groups by more than $3 \%$, data may be problematic for the total US population [44]. A particularly notable limitation of the NSDUH is that it does not include information regarding chronic pain. This omission necessarily narrowed our analysis and inhibited our 


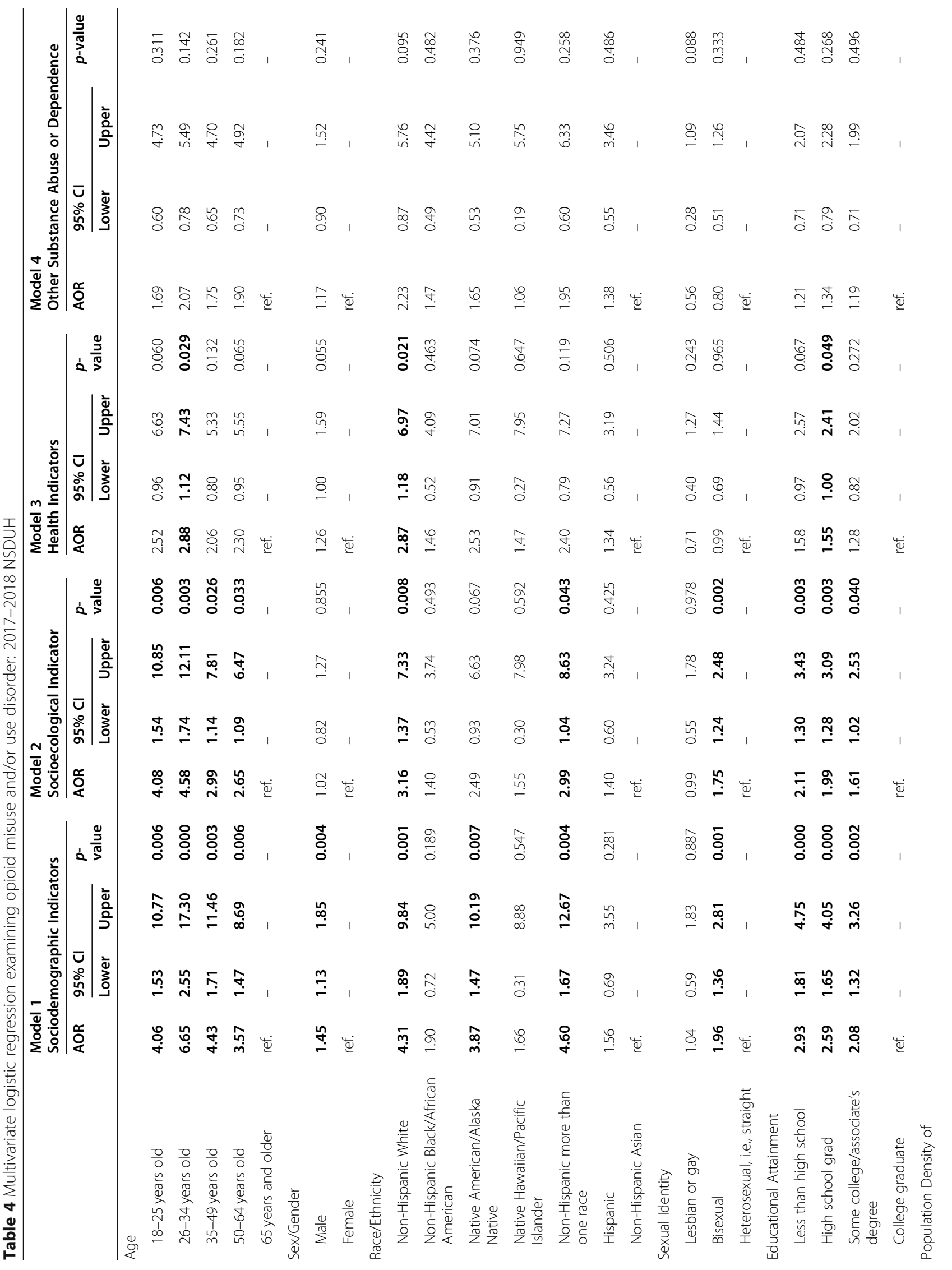




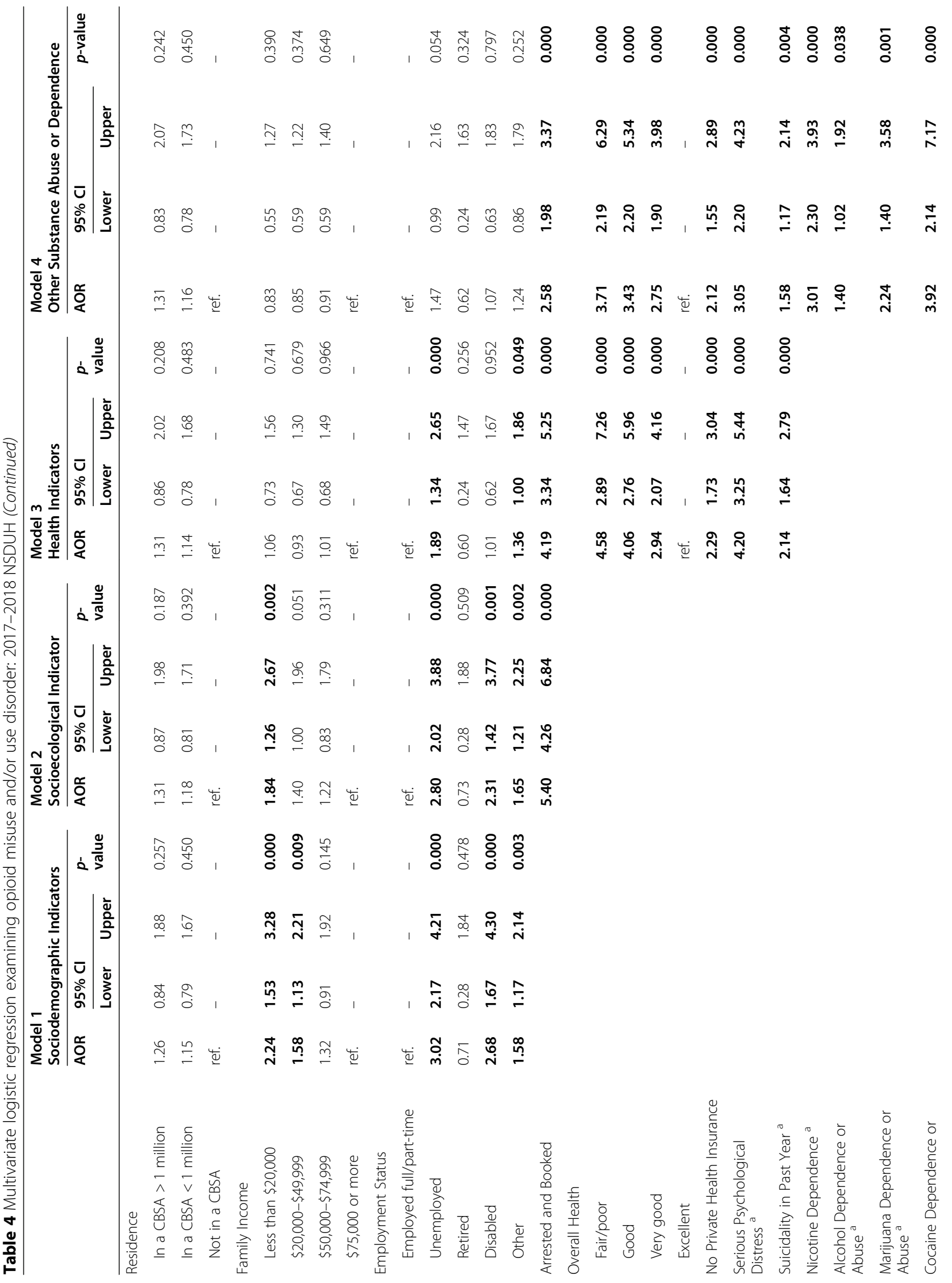




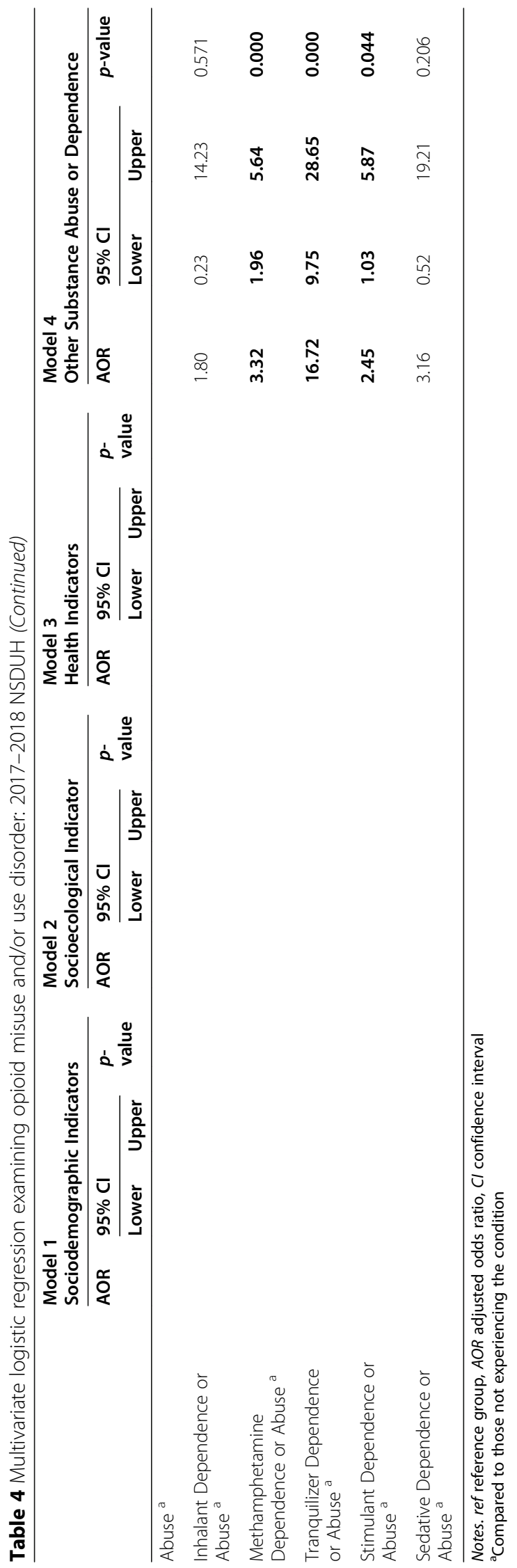


ability to create a truly comprehensive model. Another issue that may have introduced bias is participant knowledge or lack thereof concerning opioids and other substances [70]. Moreover, heroin is a less commonly used opioid and there are issues in accounting for the true prevalence of this substance use [70,71]. Finally, the opioid misuse data do not fully account for synthetic opioids like fentanyl.

\section{Conclusion}

This study provides the most recent and comprehensive risk assessment of possible biopsychosocial characteristics indicative of opioid misuse. Findings provide the population-level risk factors to improve risk assessments and to tailor future interventions to stem and ameliorate the opioid epidemic. For instance, at-risk individuals had a history of criminality, serious psychological distress, suicidality, no private health insurance, and substance dependence or abuse. Individuals, however, are not variables representative of risk factors on an outcome to opioid misuse and/or use disorder. At a population-level analysis, we must acknowledge that results of a variablecentered approach such as this work only represent findings based on a population average. More specialized approaches, such as person-centered ones, are necessary to study specific at-risk groups and opioid misuse and/or use disorder [72]. Thus, these findings serve as a population-level risk profile using the most recent US nationally representative data to inform epidemiological trends and possible large-scale interventions.

\section{Abbreviations}

AOR: Adjusted odds ratio; CBSA: Core-based statistical areas; OR: Odds ratio; US: United States

\section{Acknowledgements}

We would like to thank Claire Rowan for her valuable feedback, time, and support-all of which enhanced this work.

\section{Authors' contributions}

FAMI and TG conceived the study. FAMI designed the study. FAMI acquired, cleaned, managed, and analyzed the data under supervision of TG. All authors interpreted the results. FAMI and BS drafted the manuscript, supervised by TG and FW. PM, TG, and FW substantially modified and approved the submitted version of the manuscripts. All authors read and approved the final version of the manuscript. The content is solely the responsibility of the authors and does not necessarily reflect the views of the National Institutes of Health.

\section{Funding}

The effort of Drs. Francisco A. Montiel Ishino and Faustine Williams, and Ms. Bonita Salmeron was supported by the Division of Intramural Research, National Institute on Minority Health and Health Disparities, National Institutes of Health. The content is solely the responsibility of the authors and does not necessarily reflect the views of the National Institutes of Health. Use of these data does not imply the National Institutes of Health agrees or disagrees with any presentations, analyses, interpretations, or conclusions herein, nor was it involved in the design of the study and collection, analysis, and interpretation of data and in writing the manuscript.

\section{Availability of data and materials}

All National Survey on Drug Use and Health datasets analyzed during the current study are available in the Substance Abuse \& Mental Health Data Archive (SAMHDA) database repository, https://www.datafiles.samhsa.gov/ study-series/national-survey-drug-use-and-health-nsduh-nid13517, of which public access is open.

Ethics approval and consent to participate

The study received exemption from the Texas A\&M University Institutional Review Board as no human participants were involved in this research.

\section{Consent for publication}

Not applicable.

\section{Competing interests}

The authors declare that they have no competing interests.

\section{Author details}

${ }^{1}$ Division of Intramural Research, National Institute on Minority Health and Health Disparities, National Institutes of Health, 7201 Wisconsin Ave Ste. 533, Bethesda, MD 20814, USA. ${ }^{2}$ Center for a Livable Future, Department of Environmental Health \& Engineering, Johns Hopkins Bloomberg School of Public Health, 111 Market Place, Suite 840, Baltimore, MD 21202, USA. ${ }^{3}$ Transdisciplinary Center for Health Equity Research, College of Education and Human Development, Texas A\&M University, 4243 TAMU, 311 Blocker, College Station, TX 77843, USA.

Received: 27 February 2020 Accepted: 8 November 2020

Published online: 18 November 2020

\section{References}

1. Vowles KE, McEntee ML, Julnes PS, Frohe T, Ney JP, van der Goes DN. Rates of opioid misuse, abuse, and addiction in chronic pain: a systematic review and data synthesis. Pain. 2015;156(4):569-76.

2. Cicero TJ, Ellis MS, Surratt HL, Kurtz SP. The changing face of heroin use in the United States: a retrospective analysis of the past 50 years. JAMA Psychiatry. 2014;71(7):821-6.

3. National Institute on Drug Abuse: Opioid Overdose Crisis. https://www. drugabuse.gov/drugs-abuse/opioids/opioid-overdose-crisis. Accessed 01 June 2019.

4. Vivolo-Kantor AM, Seth P, Gladden RM, Mattson CL, Baldwin GT, Kite-Powell A, Coletta MA. Vital signs: trends in emergency department visits for suspected opioid overdoses_United States, July 2016-September 2017. Morb Mortal Weekly Rep. 2018;67(9):279.

5. Chen Q, Larochelle MR, Weaver DT, Lietz AP, Mueller PP, Mercaldo S, Wakeman SE, Freedberg KA, Raphel TJ, Knudsen AB, et al. Prevention of prescription opioid misuse and projected overdose deaths in the United States. JAMA Netw Open. 2019;2(2):-e187621.

6. Pitt AL, Humphreys K, Brandeau ML. Modeling health benefits and harms of public policy responses to the US opioid epidemic. Am J Public Health. 2018;108(10):1394-400.

7. Fraser M, Plescia M. The opioid epidemic's prevention problem. Am J Public Health. 2019;109(2):215-7.

8. Joshi S, Weiser T, Warren-Mears V. Drug, opioid-involved, and heroininvolved overdose deaths among American Indians and Alaska natives-Washington, 1999-2015. Morb Mortal Weekly Rep. 2018;67(50): 1384

9. Scholl L, Seth P, Kariisa M, Wilson N, Baldwin G. Drug and opioid-involved overdose deaths_United States, 2013-2017. MMWR Morb Mortal Wkly Rep. 2019;67:1419-27.

10. Peteet BJ. Psychosocial risks of prescription drug misuse among U.S. racial/ ethnic minorities: a systematic review. J Ethn Subst Abus. 2019;18(3):476508.

11. Nicholson HL, Vincent J. Gender differences in prescription opioid misuse among U.S. black adults. Subst Use Misuse. 2018;54(4):639-50.

12. Ford JA, Rivera FI. Nonmedical prescription drug use among Hispanics. J Drug Iss. 2008;38(1):285-310.

13. Pierce M, Hayhurst K, Bird SM, Hickman M, Seddon T, Dunn G, Millar T. Insights into the link between drug use and criminality: lifetime offending of criminally-active opiate users. Drug Alcohol Depend. 2017;179:309-16. 
14. Duncan DT, Zweig S, Hambrick HR, Palamar JJ. Sexual orientation disparities in prescription opioid misuse among U.S. adults. Am J Prev Med. 2019;56(1): $17-26$.

15. Kecojevic A, Wong CF, Corliss HL, Lankenau SE. Risk factors for high levels of prescription drug misuse and illicit drug use among substance-using young men who have sex with men (YMSM). Drug Alcohol Depend. 2015;150:156-63.

16. Schuler MS, Rice CE, Evans-Polce RJ, Collins RL. Disparities in substance use behaviors and disorders among adult sexual minorities by age, gender, and sexual identity. Drug Alcohol Depend. 2018;189:139-46.

17. Chou R, Turner JA, Devine EB, Hansen RN, Sullivan SD, Blazina I, Dana T, Bougatsos C, Deyo RA. The effectiveness and risks of long-term opioid therapy for chronic pain: a systematic review for a National Institutes of Health pathways to prevention workshop. Ann Intern Med. 2015;162(4):276-86.

18. Chen EY, Marcantonio A, Tornetta P III. Correlation between 24-hour predischarge opioid use and amount of opioids prescribed at hospital discharge. JAMA Surgery. 2018;153(2):e174859.

19. Schatman ME. The role of the health insurance industry in perpetuating suboptimal pain management. Pain Med. 2011;12(3):415-26.

20. Wettstein G. Health insurance and opioid deaths: evidence from the affordable care act young adult provision. Health Econ. 2019;28(5):666-77.

21. Novak P, Feder KA, Ali MM, Chen J. Behavioral health treatment utilization among individuals with co-occurring opioid use disorder and mental illness: evidence from a national survey. J Subst Abus Treat. 2019;98:47-52.

22. Prince JD. Correlates of opioid use disorders among people with severe mental illness in the United States. Subst Use Misuse. 2019;54(6):1024-34.

23. Ashrafioun L, Heavey S, Canarapen T, Bishop TM, Pigeon WR. The relationship between past 12-month suicidality and reasons for prescription opioid misuse. J Affect Disord. 2019;249:45-51.

24. Conroy SC, Bjork JM. Death ambivalence and treatment seeking: Suicidality in opiate addiction. Current Treatment Options in Psychiatry. 2018;5(3):291-300.

25. John WS, Zhu H, Mannelli P, Subramaniam GA, Schwartz RP, McNeely J, Wu L-T. Prevalence and patterns of opioid misuse and opioid use disorder among primary care patients who use tobacco. Drug Alcohol Depend 2019;194:468-75.

26. Rajabi A, Dehghani M, Shojaei A, Farjam M, Motevalian SA. Association between tobacco smoking and opioid use: a meta-analysis. Addict Behav. 2019;92:225-35.

27. Fernandez AC, Bush C, Bonar EE, Blow FC, Walton MA, Bohnert AS. Alcohol and drug overdose and the influence of pain conditions in an addiction treatment sample. J Addict Med. 2019;13(1):61-8

28. Kelley ML, Bravo AJ, Votaw VR, Stein E, Redman JC, Witkiewitz K. Opioid and sedative misuse among veterans wounded in combat. Addict Behav. 2019; 92:168-72.

29. Ellis MS, Kasper ZA, Cicero TJ. Twin epidemics: the surging rise of methamphetamine use in chronic opioid users. Drug Alcohol Depend. 2018;193:14-20

30. Jones CM. The paradox of decreasing nonmedical opioid analgesic use and increasing abuse or dependence - an assessment of demographic and substance use trends, United States, 2003-2014. Addict Behav. 2017:65:229-35.

31. Jones JD, Mogali S, Comer SD. Polydrug abuse: a review of opioid and benzodiazepine combination use. Drug Alcohol Depend. 2012;125(1-2):8-18.

32. Maree RD, Marcum ZA, Saghafi E, Weiner DK, Karp JF. A systematic review of opioid and benzodiazepine misuse in older adults. Am J Geriatr Psychiatry. 2016;24(11):949-63.

33. Peckham AM, Evoy KE, Covvey JR, Ochs L, Fairman KA, Sclar DA. Predictors of gabapentin overuse with or without concomitant opioids in a commercially insured U.S. population. Pharmacotherapy. 2018;38(4):436-43.

34. Grigsby TJ, Howard JT. Prescription opioid misuse and comorbid substance use: past 30-day prevalence, correlates and co-occurring behavioral indicators in the 2016 National Survey on drug use and health. Am J Addict. 2019;28(2):1-8.

35. Degenhardt L, Whiteford HA, Ferrari AJ, Baxter AJ, Charlson FJ, Hall WD, Freedman G, Burstein R, Johns N, Engell RE, et al. Global burden of disease attributable to illicit drug use and dependence: findings from the global burden of disease study 2010. Lancet. 2013;382(9904):1564-74.

36. Campbell G, Hall W, Nielsen S. What does the ecological and epidemiological evidence indicate about the potential for cannabinoids to reduce opioid use and harms? A comprehensive review. Int Rev Psychiatry 2018;30(5):91-106.

37. Winkelman TN, Chang WW, Binswanger IA. Health, polysubstance use, and criminal justice involvement among adults with varying levels of opioid use. JAMA Netw Open. 2018;1(3):e180558.
38. U.S. Department of Health and Human Services, Substance Abuse and Mental Health Services Administration, Center for Behavioral Health Statistics and Quality: National Survey on Drug Use and Health 2017 (NSDUH-2017-DS0001). https:/datafiles.samhsa.gov/. Accessed 01 June 2019.

39. U.S. Department of Health and Human Services, Substance Abuse and Mental Health Services Administration, Center for Behavioral Health Statistics and Quality: National Survey on Drug Use and Health 2018 (NSDUH-2018-DS0001). https://datafiles.samhsa.gov/. Accessed 01 June 2019.

40. Substance Abuse and Mental Health Services Administration. 2018 National Survey on drug use and health: methodological summary and definitions. Rockville: Center for Behavioral Health Statistics and Quality, Substance Abuse and Mental Health Services Administration; 2019.

41. Budget. OoMa: OMB Bulletin No. 10-02: Update of statistical area definitions and guidance on their uses. Washington: The White House; 2009.

42. Furukawa TA, Kessler RC, Slade T, Andrews G. The performance of the K6 and K10 screening scales for psychological distress in the Australian National Survey of mental health and well-being. Psychol Med. 2003;33(2): 357-62.

43. Kessler RC, Barker PR, Colpe LJ, Epstein JF, Gfroerer JC, Hiripi E, Howes MJ, Normand S-LT, Manderscheid RW, Walters EE. Screening for serious mental illness in the general population. Arch Gen Psychiatry. 2003;60(2):184-9.

44. Statistics. In: Administration, editor. CfBH: 2017 National Survey of Drug Use and Health final analytic codebook. Rockville: SAaMHS; 2018.

45. Tetrault JM, Desai RA, Becker WC, Fiellin DA, Concato J, Sullivan LE. Gender and non-medical use of prescription opioids: results from a national U.S. survey. Addiction. 2008;103(2):258-68.

46. Becker WC, Sullivan LE, Tetrault JM, Desai RA, Fiellin DA. Non-medical use, abuse and dependence on prescription opioids among U.S. adults: psychiatric, medical and substance use correlates. Drug Alcohol Depend. 2008;94(1-3):38-47.

47. Mojtabai R, Amin-Esmaeili M, Nejat E, Olfson M. Misuse of prescribed opioids in the U nited S tates. Pharmacoepidemiol Drug Saf. 2019;28(3):345-53.

48. Sullivan MD, Edlund MJ, Zhang L, Unützer J, Wells KB. Association between mental health disorders, problem drug use, and regular prescription opioid use. Arch Intern Med. 2006;166(19):2087-93.

49. Reavis JA, Looman J, Franco KA, Rojas B. Adverse childhood experiences and adult criminality: how long must we live before we possess our own lives? Perm J. 2013:17(2):44-8.

50. Merrick MT, Ports KA, Ford DC, Afifi TO, Gershoff ET, Grogan-Kaylor A. Unpacking the impact of adverse childhood experiences on adult mental health. Child Abuse Negl. 2017;69:10-9.

51. Stein MD, Conti MT, Kenney S, Anderson BJ, Flori JN, Risi MM, Bailey GL. Adverse childhood experience effects on opioid use initiation, injection drug use, and overdose among persons with opioid use disorder. Drug Alcohol Depend. 2017;179:325-9.

52. Jalali MS, Botticelli M, Hwang RC, Koh HK, McHugh RK. The opioid crisis: a contextual, social-ecological framework. Health Res Policy Syst. 2020;18(1):87.

53. Burgess DJ, Nelson DB, Gravely AA, Bair MJ, Kerns RD, Higgins DM, van Ryn M, Farmer M, Partin MR. Racial differences in prescription of opioid analgesics for chronic noncancer pain in a national sample of veterans. J Pain. 2014;15(4):447-55.

54. Connor JP, Gullo MJ, White A, Kelly AB: Polysubstance use: diagnostic challenges, patterns of use and health. Curr Opin Psychiatry 2014, 27(4).

55. Schepis T, McCabe S, Teter C. Sources of opioid medication for misuse in older adults: results from a nationally representative survey. Pain. 2018; 159(8):1543-9.

56. Nakawaki B, Crano WD. Predicting adolescents' persistence, non-persistence, and recent onset of nonmedical use of opioids and stimulants. Addict Behav. 2012;37(6):716-21.

57. Nicholson HL, Ford JA. Sociodemographic, neighborhood, psychosocial, and substance use correlates of cocaine use among black adults: findings from a pooled analysis of national data. Addict Behav. 2019;88:182-6.

58. Snyder SM, Morse SA, Bride BE. A comparison of 2013 and 2017 baseline characteristics among treatment-seeking patients who used opioids with co-occurring disorders. J Subst Abus Treat. 2019;99:134-8.

59. Schepis TS, Simoni-Wastila L, McCabe SE. Prescription opioid and benzodiazepine misuse is associated with suicidal ideation in older adults. Int J Geriatr Psychiatry. 2019;34(1):122-9.

60. McClure FL, Niles JK, Kaufman HW, Gudin J. Concurrent Use of Opioids and Benzodiazepines: Evaluation of Prescription Drug Monitoring by a United States Laboratory. J Addict Med. 2017;11(6):420-6. 
61. Mair C, Sumetsky N, Burke JG, Gaidus A. Investigating the social ecological contexts of opioid use disorder and poisoning hospitalizations in Pennsylvania. Journal of Studies on Alcohol and Drugs. 2018;79(6):899-908.

62. Witkiewitz K, Vowles KE. Alcohol and opioid use, co-use, and chronic pain in the context of the opioid epidemic: a critical review. Alcohol Clin Exp Res. 2018:42(3):478-88.

63. Moore KE, Hacker RL, Oberleitner L, McKee SA. Reentry interventions that address substance use: a systematic review. Psychol Serv. 2020;17(1):93-101.

64. Crowley RA, Kirschner N. The integration of care for mental health, substance abuse, and other behavioral health conditions into primary care: executive summary of an American College of Physicians position paper. Ann Intern Med. 2015;163(4):298-9.

65. Lones CE, Bond GR, McGovern MP, Carr K, Leckron-Myers T, Hartnett T, Becker DR. Individual placement and support (IPS) for methadone maintenance therapy patients: a pilot randomized controlled trial. Adm Policy Ment Health Ment Health Serv Res. 2017;44(3):359-64.

66. Kendall S, Redshaw S, Ward S, Wayland S, Sullivan E. Systematic review of qualitative evaluations of reentry programs addressing problematic drug use and mental health disorders amongst people transitioning from prison to communities. Health Justice. 2018;6(1):4.

67. Drake RE, Mueser KT, Brunette MF, McHugo GJ. A review of treatments for people with severe mental illnesses and co-occurring substance use disorders. Psychiatric Rehabilitation J. 2004;27(4):360-74.

68. Health Resources \& Services Administration: Opioid 'Syndemic' Tests Rural America. https://www.hrsa.gov/enews/past-issues/2016/november-17/ opioid-syndemic.html. Accessed 23 Oct 2020.

69. Perlman DC, Jordan AE. The syndemic of opioid misuse, overdose, HCV, and HIV: structural-level causes and interventions. Curr HIV/AIDS Rep. 2018;15(2): 96-112.

70. Palamar JJ. Barriers to accurately assessing prescription opioid misuse on surveys. Am J Drug Alcohol Abuse. 2018;45(2):1-7.

71. Center for Behavioral Health Statistics. In: Administration SAaMHS, editor. 2017 National Survey of Drug Use and Health final analytic codebook. Rockville: Substance Abuse and Mental Health Services Administration; 2018.

72. Montiel Ishino FA, Gilreath T, Williams F. Finding the hidden risk profiles of the United States opioid epidemic: using a person-centered approach on a national dataset of noninstitutionalized adults reporting opioid misuse. Int J Env Res Public Health. 2020;17(12):E4321.

\section{Publisher's Note}

Springer Nature remains neutral with regard to jurisdictional claims in published maps and institutional affiliations.

Ready to submit your research? Choose BMC and benefit from:

- fast, convenient online submission

- thorough peer review by experienced researchers in your field

- rapid publication on acceptance

- support for research data, including large and complex data types

- gold Open Access which fosters wider collaboration and increased citations

- maximum visibility for your research: over $100 \mathrm{M}$ website views per year

At $\mathrm{BMC}$, research is always in progress.

Learn more biomedcentral.com/submissions 